\title{
Glutamate Decarboxylase 1 Overexpression as a Poor Prognostic Factor in Patients with Nasopharyngeal Carcinoma
}

\author{
Yi-Ying Lee1, Tung-Bo Chao',3, Ming-Jen Sheu ${ }^{4}$, Yu-Feng Tian"5,6, Tzu-Ju Chen7, Sung-Wei Lee ${ }^{8}$, Hong-Lin \\ He$^{9}$, I-Wei Chang9 ${ }^{9}$, Chung-Hsi Hsing10, Ching-Yih Lin ${ }^{4,11 \bowtie}$,Chien-Feng Li7,12,13,14凶 \\ 1. Department of Pathology, Chi-Mei Medical Center, Liouying, Taiwan; \\ 2. Departments of Colorectal Surgery, Yuan's General Hospital, Kaohsiung, Taiwan; \\ 3. Department of Health Business Administration, Meiho University, Pingtung, Taiwan; \\ 4. Division of Gastroenterology and Hepatology, Department of Internal Medicine, Chi-Mei Medical Center, Tainan, Taiwan; \\ 5. Division of General Surgery, Chi Mei Medical Center, Tainan, Taiwan; \\ 6. Department of Health and Nutrition, Chia Nan University of Pharmacy \& Science, Tainan, Taiwan; \\ 7. Department of Pathology, Chi-Mei Medical Center, Tainan, Taiwan; \\ 8. Department of Radiation Oncology, Chi-Mei Medical Center, Liouying, Tainan, Taiwan \\ 9. Department of Pathology, E-DA Hospital, I-Shou University, Kaohsiung, Taiwan; \\ 10. Department of Anesthesiology, Kaohsiung Chang Gung Memorial Hospital and Chang Gung University College of Medicine, Kaohsiung, Taiwan; \\ 11. Department of Leisure, Recreation, and Tourism Management, Southern Taiwan University of Science and Technology, Tainan, Taiwan; \\ 12. National Institute of Cancer Research, National Health Research Institutes, Tainan, Taiwan; \\ 13. Department of Biotechnology, Southern Taiwan University of Science and Technology, Tainan, Taiwan; \\ 14. Institute of Clinical Medicine, Kaohsiung Medical University, Kaohsiung, Taiwan. \\ $\triangle$ Corresponding authors: Chien-Feng Li, M.D., PhD., Division of Cinical Pathology, Chi Mei Medical Center, Tainan 710, Taiwan. E-mail: angelo.p@yahoo.com.tw or \\ Ching-Yih Lin, M.D., Division of Gastroenterology and Hepatology, Department of Internal Medicine, Chi-Mei Medical Center, Tainan 710, Taiwan. E-mail: \\ d840811@mail.chimei.org.tw.
}

() Ivyspring International Publisher. Reproduction is permitted for personal, noncommercial use, provided that the article is in whole, unmodified, and properly cited. See http://ivyspring.com/terms for terms and conditions.

Received: 2016.03.27; Accepted: 2016.06.07; Published: 2016.07.27

\begin{abstract}
Background: Glutamate decarboxylase 1 (GADI) which serves as a rate-limiting enzyme involving in the production of $y$-aminobutyric acid (GABA), exists in the GABAergic neurons in the central nervous system (CNS). Little is known about the relevance of GADI to nasopharyngeal carcinoma (NPC). Through data mining on a data set derived from a published transcriptome database, this study first identified GADI as a differentially upregulated gene in NPC. We aimed to evaluate GADI expression and its prognostic effect on patients with early and locoregionally advanced NPC.

Methods: We evaluated GADI immunohistochemistry and performed an $\mathrm{H}$-score analysis on biopsy specimens from 124 patients with nonmetastasized NPC receiving treatment. GADI overexpression was defined as an $\mathrm{H}$ score higher than the median value. The findings of such an analysis are correlated with clinicopathological behaviors and survival rates, namely disease-specific survival (DSS), distant-metastasis-free survival (DMeFS), and local recurrence-free survival (LRFS) rates.

Results: GADI overexpression was significantly associated with an increase in the primary tumor status $(p<0.001)$ and American Joint Committee on Cancer (AJCC) stages III-IV $(p=0.002)$ and was a univariate predictor of adverse outcomes of DSS $(p=0.002)$, DMeFS $(p<0.0001)$, and LRFS $(p=0.001)$. In the multivariate comparison, in addition to advanced AJCC stages III-IV, GADI overexpression remained an independent prognosticator of short DSS $(p=0.004$, hazard ratio $=2.234)$, DMeFS $(p<$ 0.001 , hazard ratio $=4.218)$, and LRFS $(p=0.013$, hazard ratio $=2.441)$ rates.

Conclusions: Our data reveal that GADI overexpression was correlated with advanced disease status and may thus be a critical prognostic indicator of poor outcomes in NPC and a potential therapeutic target to facilitate the development of effective treatment modalities.
\end{abstract}

Key words: GAD1, nasopharyngeal carcinoma, glutamate acid decarboxylase $1, \gamma$-aminobutyric acid, transcriptome, Prognosis. 


\section{Introduction}

Nasopharyngeal carcinoma (NPC), known as an endemic malignancy in southeast Asia, southern China, and Taiwan, is caused by multifactorial etiologies including infection by Epstein-Barr virus (EBV), environmental factors (e.g., smoking and consumption of preserved food), and hereditary factors [1-4]. According to the present World Health Organization (WHO) classification, several histological subtypes of NPC are available including squamous-cell carcinoma (SCC), nonkeratinizing carcinoma (differentiated or undifferentiated), and basaloid SCC [5]. Approximately 99\% of NPCs are classified as differentiated or undifferentiated nonkeratinizing carcinoma in endemic areas, showing a strong association with EBV infection $[5,6]$. Radiotherapy is still the first-line therapy for early-stage NPC, whereas cisplatin-based chemoradiotherapy is currently recommended for more advanced disease stages involving a diminished distant metastatic rate and improved locoregional control [7-10]. However, a considerable proportion of patients develop a certain degree of resistance to chemoradiotherapy, which may result in locoregional recurrence and distant metastasis in certain patients [9-11]. Hence, identifying prognostic biomarkers for improving the treatment efficacy and risk stratification is crucial, and this can facilitate the development of novel and personalized therapeutic treatment for patients with NPC.

We reassessed a published transcriptome of NPC (GSE12452) to explore prominent differentially expressed genes. We identified glutamate decarboxylase 1 (GAD1) as a prominently upregulated gene among the pathways associated with glutamate decarboxylase activity (GO:0004351). Glutamine was demonstrated to play a role in tumor metabolism through tricarboxylic acid cycle-dependent and independent pathways [12-14]. Glutamine metabolism alteration is extremely crucial and has led to the development of prognostic adjunct and therapeutic targets for cancer therapy [12-14]. In addition to playing a role in the synthesis of the amino acids proline and arginine, glutamine-derived glutamate plays a central role in the synthesis of the antioxidant glutathione, which is pivotal in managing oxidative stress in cancer [15]. GAD1 is present in the GABAergic neurons in the CNS, functioning as a rate-limiting enzyme which catalyzes the decarboxylation of glutamate to $\gamma$-aminobutyric acid (GABA) [16]. Human beings have three known isoforms of GAD: GAD1, 25, and 67 (67, 25, and 65 $\mathrm{kDa}$, respectively) $[17,18]$. GAD1 is involved in certain psychiatric diseases and insulin-dependent diabetes mellitus $[19,20]$. Considerably high GAD1 expression has been recently observed in neoplasms such as oral SCC (OSCC), colorectal cancer, breast cancer, and gastric cancer [16, 21, 22]. In addition, GAD1 might be a prostate-specific tissue biomarker because it is considerably overexpressed in patients with metastatic prostate cancers [23, 24]. GAD1 and GABA were also found to play a role in regulating cancer cells, particularly in the proliferation of stem cells [25]. However, little is known about the role of GAD1 expression in NPC.

It has never been comprehensively investigated the significance of GAD1 expression in a well-established cohort of NPC tissues, as well as its association with different clinicopathological variables. Therefore, we analyzed GAD1 immunoexpression in NPC specimens and its correlation with various clinicopathological factors and prognostic implications.

\section{Materials and Methods}

\section{Analysis of published transcriptome data sets}

To identify genes that play a critical role in the pathogenesis of NPC, we re-examined the transcriptome data set published in the Gene Expression Omnibus (GSE12452) of NPC tissues ( $\mathrm{n}=$ 31) versus non-tumorous nasopharyngeal epithelial tissues $(\mathrm{n}=10)$ enriched through laser-capture microdissection for target cells [26-29]. All probe sets were analyzed without filtering or preselection by means of importing raw CEL files of the Affymetrix HUMAN Genome U133 Plus 2.0 microarray platform into Nexus Expression 3 software (BioDiscovery). Supervised functional profiling and comparative analysis were done, as described previously, to identify prominent differentially expressed genes by emphasizing pathways involving glutamate decarboxylase activity in Gene Ontology (GO:0004351) [27-29]. We identified those that with $p$ $<0.01$ and a log2-transformed expression fold change $>0.1$ for further evaluation.

\section{Patients and tumor specimens}

All institutional review board (IRB)-approved NPC tissues were procured for the study (IRB10501-006). In total, 146 formalin-fixed, paraffin-embedded biopsy specimens were retrieved from patients with NPC at Chi-Mei Medical Center between January 1993 and December 2002. Of these patients, 10 with systemic involvement and 12 who did not accomplish the standard treatment course or were lost to follow-up were excluded. The remaining 124 patients were excluded from this retrospective study. No events of distant metastases were identified at the initial diagnosis for all of these patients. Two pathologists (TJC and HLH) reappraised the 
histologic subtypes based on the criteria of the current WHO classification [5]. Tumor staging was re-examined according to the seventh American Joint Committee on Cancer (AJCC) system [30].

\section{Immunohistochemical staining and assessment of GAD1 expression}

Tissue sections (thickness $=3 \mu \mathrm{m}$ ) were obtained from paraffin-embedded blocks. Deparaffinized slides were then rehydrated with ethanol and heated using microwave treatment for retrieving antigen epitopes in $10 \mathrm{mM}$ citrate buffer $(\mathrm{pH}$ 6) for 7 minutes. Furthermore, 3\% $\mathrm{H} 2 \mathrm{O} 2$ was used to quench endogenous peroxidase. The slides were washed for 15 minutes by using Tris-buffered saline and then incubated with a primary polyclonal antibody targeting GAD1 (1:100; Clone EPR2550, Abcam) for 1 hour. A ChemMate EnVision kit (DAKO, K5001, Carpinteria, CA) was applied for identifying primary antibodies. After their incubation with the secondary antibody for 30 minutes and 3,3-diaminobenzidine for 5 minutes, the slides were counterstained with hematoxylin. Furthermore, a human lung tissue-containing respiratory epithelium sample was used as the positive control, according to the manufacturer's recommendation, and rabbit serum IgG-replacing primary antibody served as the negative control. Blinded to the clinical and follow-up information, two pathologists (TJC \& HLH) examined GAD1 immunoexpression by using a multiheaded microscope to reach a consensus on the $\mathrm{H}$ score, as reported in previous studies [27-29]. Those that express both cytoplasmic and nuclear staining are determined as immunopositive. In brief, we calculated the score by using the following equation: $H$ score $=\sum P i(i+1)$, where $i$ is the intensity (range, $0-3)$ and $P i$ is the percentage of stained tumor cells varying from $0 \%$ to $100 \%$. Tumors with higher $\mathrm{H}$ scores than the median values of all examined cases were classified as having high expression.

\section{Treatment and follow-up}

In total, 114 of the 124 patients with NPC were regularly monitored after undergoing radiotherapy until death or their final appointment (mean follow-up duration, 67 months; range, 3-141 months). All 124 patients completed the radiotherapy course according to the published protocol, with a daily fractionation of 180-200 cGy and five fractions weekly to reach a total dose of no less than 7000 cGy [31]. For those with stage II-IV diseases, at least three cycles of cisplatin-based chemotherapy were adopted. Nonetheless, one patient with stage II and four patients with stage IV diseases did not receive current chemotherapy but only radiation therapy because of their poor general health condition. The method of administering radiotherapy was generally uniform in this study. However, seven patients treated in the earlier phase of the cohort were unavailable for instant post-therapy image evaluations that could be used to establish the baseline for determining the treatment effect. Moreover, 110 complete and 7 partial tumor regressions determined through the previously reported methods were adjusted according to the WHO criteria [32].

\section{Statistical analysis}

SPSS 14 software was used for statistical analyses, and the chi-squared and Mann-Whitney U test was used for evaluating the associations between the GAD1 expression status and various clinicopathological variables and the differential expression between primary and metastatic lesions, respectively. The analytic endpoints were disease-specific survival (DSS), distant-metastasis-free survival (DMeFS), and local recurrence-free survival (LRFS), calculated from the start date of radiotherapy to the date the event developed. Moreover, we used the Kaplan-Meier method to plot survival curves and performed log-rank tests to evaluate prognostic significance levels. Multivariate analysis was done using the Cox proportional hazards model. Two-sided tests were performed, with $p<0.05$ considered significant for all analyses.

\section{Results}

\section{GADI serves as the only differentially upregulated gene involved in the glutamate decarboxylase activity}

From the data set of 31 NPC cases in the published transcriptome, we analyzed eight probes covering two genes participated in glutamate decarboxylase activity. Among these genes, GAD1 was the only differentially expressed gene with a significant statistical power $(p=0009)$ and considerable $\log 2$-transformed expression (log2 ratio $=0.3746$ ) that met the selection criteria for further evaluation (Fig. 1 and Table 1).

\section{Immunohistochemical expression of GADI and its associations with clinicopathological parameters}

As demonstrated in Table 2, the 124 patients with NPC involved 95 males and 29 females, with a mean age of 48.6 years (range, 20-83 years). Moreover, 38 patients were classified as stage I-II and 86 as stage III-IV. Although GAD1 immunoreactivity was negligible in the non-tumorous nasopharyngeal epithelium with and without squamous metaplasia (Figs. 2a and 2b), it was discernible in certain tumor 
samples (Figs. 2c and 2d) and was significantly associated with the evaluated primary tumor status $(p$ $<0.001)$ and advanced AJCC stages $(p=0.002)$. However, GAD1 immunoexpression was not associated with other clinicopathological variables including histological types. Of note, in six patients whose primary and metastatic tumor lesions were available, the metastatic depositions demonstrated significant higher GAD1 expression than their primary tumors ( $p=0.015$, Fig. $2 \mathrm{e}$ and $2 \mathrm{f}$, respectively).

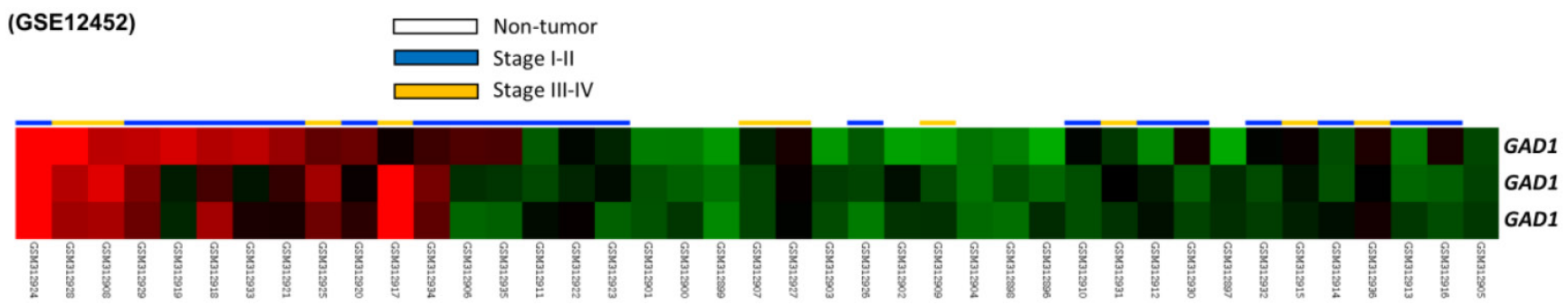

Figure 1. Analysis of gene expression from a published transcriptome dataset of NPC (GSE12452) demonstrating that GADI serves as a prominently upregulated gene among the pathways associated with glutamate decarboxylase activity (GO:0004351) and is the significant gene differentially expressed in the tumor versus non-tumor, as well as high-stage (III-IV) versus low-stage (I-II) tumors.
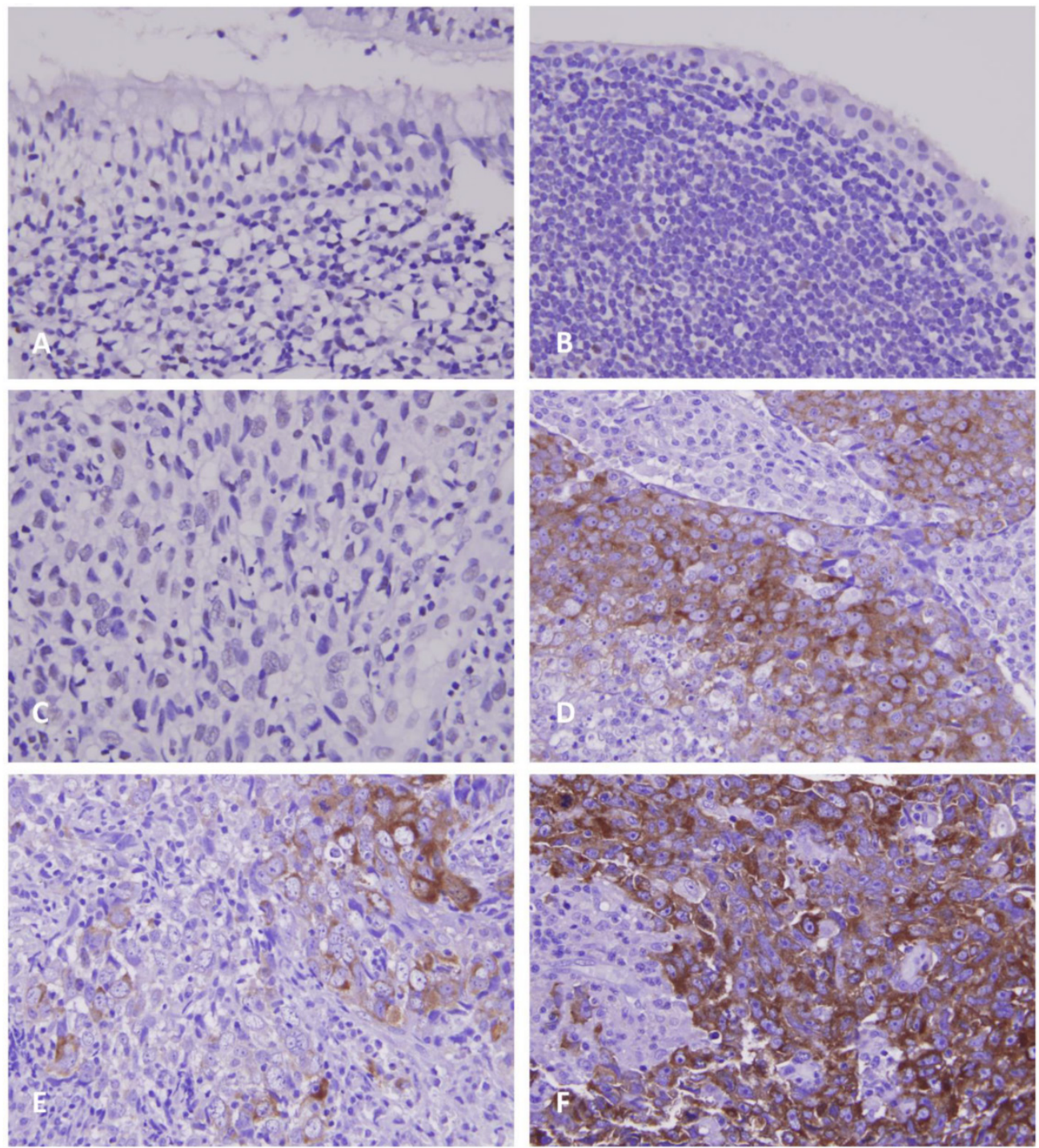

Figure 2. Photomicrographs of GADI immunoexpression. In normal nasopharyngeal mucosa with (A, X200) and without (B, X400) squamous metaplasia, there is nearly no or faint immunopositivity with GAD1. In NPC tissues, the tumor cells show weak (C, X400) or diffusely strong (D, X400) staining of GADI marker in representative low- and high-expression cases, respectively. Evaluation of GADI expression in representative primary NPC tissue (E, X400) and metastatic nodal tissue $(F, X 400)$ demonstrates more diffusely strong staining result in the metastatic depositions. 
Table 1. Summary of prominent differentially expressed genes associated with glutamate decarboxylase activity (GO:0004351) and with tumorigenesis of nasopharyngeal carcinoma (NPC) in the NPC transcriptome (GSE12452).

\begin{tabular}{|c|c|c|c|c|c|}
\hline \multirow[t]{2}{*}{ Probe } & \multicolumn{2}{|c|}{ Comparing tumor to non-tumor } & \multirow{2}{*}{$\begin{array}{l}\text { Gene } \\
\text { Symbol }\end{array}$} & \multirow[t]{2}{*}{ Gene Name } & \multirow[t]{2}{*}{ Molecular Function } \\
\hline & $\begin{array}{l}\text { Comparison } \\
\text { log ratio }\end{array}$ & $\begin{array}{l}\text { Comparison } \\
\text { p-value }\end{array}$ & & & \\
\hline 205278_at & 2.4426 & $<0.0001$ & GAD1 & $\begin{array}{l}\text { glutamate decarboxylase } \\
1 \text { (brain; } 67 \mathrm{kDa} \text { ) }\end{array}$ & $\begin{array}{l}\text { carboxy-lyase activity, catalytic activity, glutamate decarboxylase } \\
\text { activity, lyase activity, protein binding, pyridoxal phosphate binding }\end{array}$ \\
\hline 206669_at & 0.6126 & 0.0015 & GAD1 & $\begin{array}{l}\text { glutamate decarboxylase } \\
1 \text { (brain; } 67 \mathrm{kDa})\end{array}$ & $\begin{array}{l}\text { carboxy-lyase activity, catalytic activity, glutamate decarboxylase } \\
\text { activity, lyase activity, protein binding, pyridoxal phosphate binding }\end{array}$ \\
\hline 206670_s_at & 0.3746 & 0.0009 & GAD1 & $\begin{array}{l}\text { glutamate decarboxylase } \\
1 \text { (brain; } 67 \mathrm{kDa})\end{array}$ & $\begin{array}{l}\text { carboxy-lyase activity, catalytic activity, glutamate decarboxylase } \\
\text { activity, lyase activity, protein binding, pyridoxal phosphate binding }\end{array}$ \\
\hline
\end{tabular}
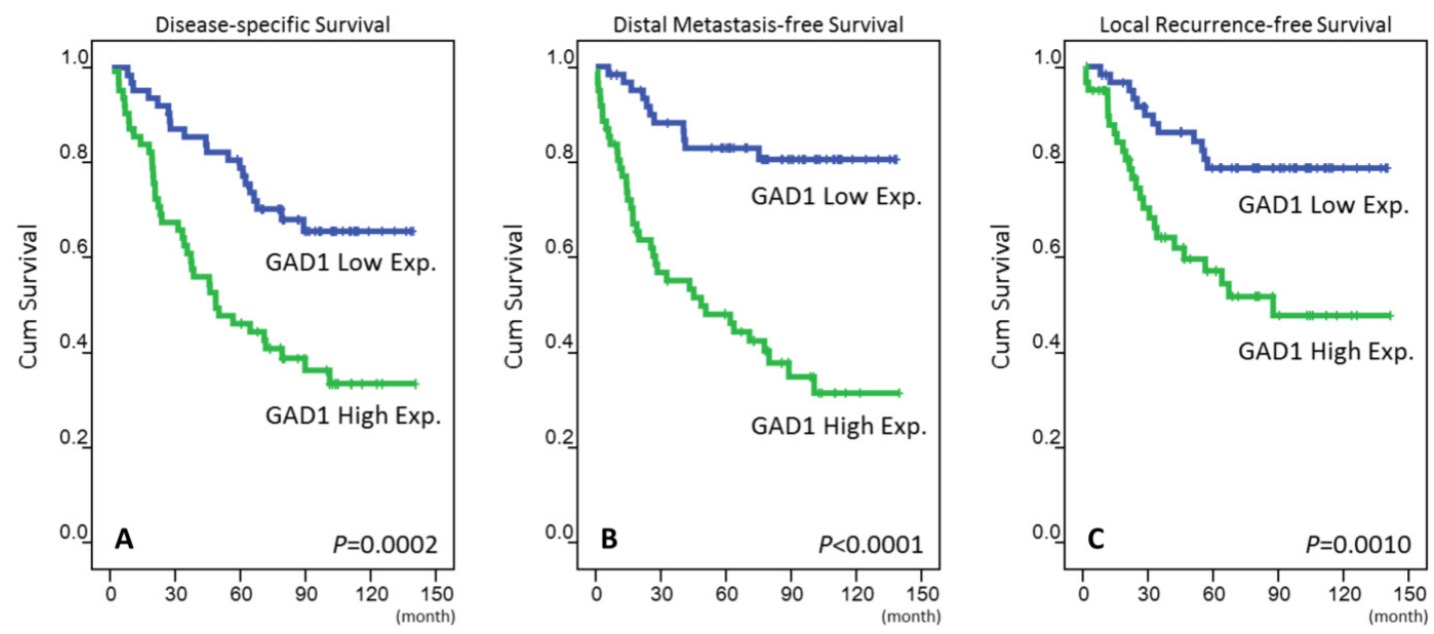

Figure 3. Kaplan-Meier survival analysis revealing that high expression of GADI predicts poorer disease-specific survival (A), distant metastasis-free survival (B), and local recurrence-free survival (C).

Table 2. Associations between GADI expression and other crucial clinicopathological variables.

\begin{tabular}{lllll}
\hline Parameters & Category & \multicolumn{2}{c}{ GAD1 Exp. } & p-value \\
\cline { 3 - 5 } & & Low & High & \\
\hline Gender & Male & 46 & 49 & 0.524 \\
\multirow{2}{*}{ Age (years) } & Female & 16 & 13 & \\
\multirow{2}{*}{ Primary tumor (pT) } & <60 years & 47 & 51 & 0.378 \\
& $>=60$ years & 15 & 11 & \\
Nodal status (N) & T3-T2 & 50 & 30 & $<0.001^{*}$ \\
& N0-N1 & 12 & 32 & \\
Stage & N2-N3 & 35 & 21 & 0.012 \\
\multirow{3}{*}{ Histological grade } & I-II & 27 & 41 & \\
& III-IV & 35 & 51 & $0.002^{*}$ \\
& Keratinizing & 2 & 3 & 0.728 \\
EBER & Non-keratinizing & 29 & 25 & \\
& Undifferentiated & 31 & 34 & \multirow{2}{*}{0.315} \\
& Negative & 0 & 1 & \\
\hline
\end{tabular}

*, Statistically significant.

\section{Prognostic effect of GADI expression}

The mean follow-up duration was 67 months (range, 3-141 months). For those three analyzing survival endpoints (Table 3), patients with T3-4, N2-3, and AJCC stage III-IV tumors at the initial presentation were significantly correlated with poor outcomes in the univariate analysis. High GAD1 expression in patients with NPC was also a predictor of an aggressive clinical course, with significantly short DSS ( $p=0.0002$, Fig. 3a), DMeFS $(p<0.0001$, Fig. $3 b)$, and LRFS $(p=0.001$, Fig. $3 c)$ rates. In the multivariate comparison (Table 4), in addition to AJCC stages III-IV, high GAD1 expression remained an independent prognosticator for DSS $(p=0.004$, hazard ratio $=2.234)$, DMeFS $(p<0.001$, hazard ratio $=$ $4.218)$, and LRFS $(p=0.013$, hazard ratio $=2.441)$.

\section{Discussion}

Nearly $15 \%-20 \%$ of patients with NPC have distant metastasis, even after receiving concurrent chemoradiation therapies, accounting for the majority of disease mortality [1, 11, 33, 34]. Therefore, developing more effective treatments for effectively managing high-risk patients by stratifying and identifying prognostic and predictive biomarkers for invasive cancer cells is imperative. We re-examined differentially expressed genes in a published transcriptome data set, and we determined that the GAD1 gene was the most significantly upregulated one among the DNA topological change-associated genes in NPC tissues. Our study is the first to report that GAD1 immunoexpression is associated with differential expression levels in NPC cases. In 
Table 3. Univariate log-rank analyses.

\begin{tabular}{|c|c|c|c|c|c|c|c|c|}
\hline \multirow[t]{2}{*}{ Parameters } & \multirow[t]{2}{*}{ Category } & \multirow{2}{*}{$\begin{array}{l}\text { No. of } \\
\text { case }\end{array}$} & \multicolumn{2}{|l|}{ DSS } & \multicolumn{2}{|c|}{ DMeFS } & \multicolumn{2}{|l|}{ LRFS } \\
\hline & & & $\begin{array}{l}\text { No. of } \\
\text { event }\end{array}$ & p-value & $\begin{array}{l}\text { No. of } \\
\text { event }\end{array}$ & $\mathrm{p}$-value & $\begin{array}{l}\text { No. of } \\
\text { event }\end{array}$ & $\mathrm{p}$-value \\
\hline Gender & Male & 95 & 45 & 0.7870 & 38 & 0.6128 & 30 & 0.3240 \\
\hline \multirow[t]{2}{*}{ Age (years) } & $<60$ years & 98 & 48 & 0.8600 & 42 & 0.3091 & 29 & 0.8206 \\
\hline & $>=60$ years & 26 & 11 & & 7 & & 8 & \\
\hline \multirow{2}{*}{$\begin{array}{l}\text { Primary tumor } \\
(\mathrm{pT})\end{array}$} & $\mathrm{T} 1-\mathrm{T} 2$ & 80 & 32 & $0.0289^{*}$ & 25 & $0.0085^{*}$ & 19 & $0.0180^{*}$ \\
\hline & T3-T4 & 44 & 27 & & 24 & & 18 & \\
\hline \multirow[t]{2}{*}{ Nodal status (N) } & N0-N1 & 56 & 18 & $0.0008^{*}$ & 17 & $0.0132^{*}$ & 12 & $0.0160^{*}$ \\
\hline & N2-N3 & 68 & 41 & & 32 & & 25 & \\
\hline \multirow[t]{2}{*}{ Stage } & I-II & 38 & 10 & $0.0020^{*}$ & 9 & $0.0072^{*}$ & 5 & $0.0026^{*}$ \\
\hline & III-IV & 86 & 49 & & 40 & & 32 & \\
\hline \multirow[t]{2}{*}{ Histological grade } & Keratinizing/Non-keratinizing & 47 & 20 & 0.1980 & 17 & 0.2753 & 15 & 0.9521 \\
\hline & Undifferentiated & 77 & 39 & & 32 & & 22 & \\
\hline EBER & Positive & 123 & 58 & & 48 & & 37 & \\
\hline \multirow[t]{2}{*}{ GAD1 Exp. } & Low Exp. (H-score<median) & 62 & 20 & $0.0002^{*}$ & 11 & $<0.0001^{*}$ & 12 & $0.0010^{*}$ \\
\hline & High Exp. (H-score>=median) & 62 & 39 & & 38 & & 25 & \\
\hline
\end{tabular}

*, Statistically significant; DSS, disease-specific survival; DMeFS, distal metastasis-free Survival; LRFS, local recurrence-free survival

Table 4. Multivariate survival analyses.

\begin{tabular}{|c|c|c|c|c|c|c|c|c|c|c|}
\hline \multirow[t]{2}{*}{ Parameter } & \multirow[t]{2}{*}{ Category } & \multicolumn{3}{|l|}{ DSS } & \multicolumn{3}{|c|}{ DMeFS } & \multicolumn{3}{|l|}{ LRFS } \\
\hline & & H.R & $95 \% \mathrm{CI}$ & p-value & H.R & $95 \% \mathrm{CI}$ & $\mathrm{p}$-value & H.R & $95 \% \mathrm{CI}$ & p-value \\
\hline \multirow[t]{2}{*}{ Stage } & I-II & 1 & - & $0.023^{*}$ & 1 & - & 0.121 & 1 & & $0.023^{*}$ \\
\hline & III-IV & 2.246 & $1.118-4.513$ & & 1.796 & $0.856-3.769$ & & 3.057 & $1.168-8.002$ & \\
\hline \multirow[t]{2}{*}{ GAD1 Exp. } & Low Exp. & 1 & - & $0.004^{*}$ & 1 & - & $<0.001^{*}$ & 1 & - & $0.013^{*}$ \\
\hline & High Exp. & 2.234 & $1.284-3.887$ & & 4.218 & $2.121-8.389$ & & 2.441 & $1.207-4.935$ & \\
\hline
\end{tabular}

*, Statistically significant; DSS, disease-specific survival; DMeFS, distal metastasis-free Survival; LRFS, local recurrence-free survival

particular, GAD1 overexpression was significantly associated with increased primary tumor status levels and AJCC stages III-IV, and it appeared to be a prognosticator of adverse outcomes of DSS, DMeFS, and LRFS in the univariate analysis. Moreover, GAD1 overexpression, together with advanced AJCC stages III-IV, remained prognostically independent for low DSS, DMeFS, and LRFS rates in the multivariate comparison.

Previous evidence indicate that EBV infection plays an oncogenic role in the tumorigenesis of NPC [5]. Non-keratinizing carcinoma (differentiated or undifferentiated) is consistently associated with EBV infection with high reported infection up to $98 \%$ of all NPCs, and accounts for the majority in endemic regions such as Taiwan [35]. In our study, 119 out of 124 cases were classified as non-keratinizing or undiffereintated carcinoma NPCs and all NPC cases (except one) were identified to express EBER, thus supporting the previously validated results. The only one EBER-negative NPC was as a keratinizing squamous cell carcinoma. However, we could not demonstrate the prognostic significance of EBER status and high GAD1 expression because of the high prevalence of EBV infection in Taiwan. Notably, the WHO-classification-based histological stratification failed to demonstrate a significant statistical prognosticator in the univariate analysis. Although most of the analyzed cases $(n=119)$ were classified as non-keratinizing carcinoma (differentiated or undifferentiated), only five cases were diagnosed with keratinizing carcinoma. It was unable to show statistical significance when dichotomized into low and high GAD1 expression according to the histologic subtypes. Kimura et al. [16] identified that GAD1 overexpression was associated with tumor invasiveness metastasis of OSCC and no differences were noted between the histopathological grade. We therefore hypothesized that high GAD1 expression was correlated with advanced NPC regardless of the histologic subtypes.

GABA was originally discovered as a primarily inhibitory neurotransmitter present in the mammalian brain [36]. The dysregulation of GABA and GAD1 has been reported to be associated with several neuronal diseases such as schizophrenia, bipolar disorder, Parkinson disease, and cerebellar disorders [22, 37]. Moreover, GABA and GAD1 levels are considerably increased in several solid organ cancers including oral, breast, gastric, and colorectal cancers, although heterogeneity exists in the extent of overproduction among such cancers $[16,21,22]$. In the current study, we also found that a high GAD1 expression level was correlated with advanced-stage 
cancer, including the development of distant metastasis, and shorter survival rates in patients with NPC. This implies that an altered GAD1 expression level plays a critical role in tumor invasiveness. Yan et al. [22] recently elucidated that DNA methylation in the GAD1 promoter region plays a pivotal role in GAD1 activation in cancer cells; they also identified increased GAD1 expression levels in mucinous colon cancer, and this increase has been revealed to result in poor responses to 5-fluorouracil-, oxaliplatin-, and irinotecan-based regimens [22, 38, 39]. These results are similar to our findings.

Our results are further supported by those of studies focusing on the proliferative effects of GABA on neoplastic cells and the GAD1 and GABA receptor expression in several malignancies [40-43]. It implied that a metabolic antagonist that converts glutamate into GABA, but not glutamine, is preferred for neoplasms with poor outcomes [44]. Furthermore, increased GABA expression and GAD activity may be involved in the invasiveness of prostate cancer cells $[21,23]$. Previous reports have also revealed that GAD1 can serve as a specific marker for prostate tissues [24, 44]. Jaraj et al. [24] identified that GAD1 is expressed in both benign and malignant prostate tissues, with a negative correlation with an increasing Gleason score, thus implying that GAD1 is a negative prognosticator. This result is different from our results that reveal that the observed high GAD1 expression was associated with increased primary tumor status levels and advanced disease stages. In general, higher Gleason scores are correlated with poor disease outcomes in patients with prostate cancers [45]. However, a considerable interobserver discrepancy was observed in grading the Gleason score, and a new grading system for simplifying the previously reported patterns is proposed in the International Society of Urological Pathology Urological Pathology Consensus Conference [45]. This may partially explain the discrepancy between the data of the present study and those reported by Jaraj et al. [24].

Kimura et al. [16] proposed that the GAD1/ $\beta$-catenin/MMP7 interaction may play crucial and diverse roles in the early detection of nodal metastasis and that it may serve as an effective treatment target for preventing distant metastasis in OSCCs. This interaction has been demonstrated to be $\beta$-catenin centric and crucial in Wnt signal transduction, gene activation and neoplasm [46-48]. Furthermore, several studies have identified that $\beta$-catenin is not only be involved in cell proliferation and survival but may also play an essential role in the development of metastases in some malignancies including NPC [49-50]. Although the mechanisms of
GAD1 and $\beta$-catenin remain unclear, Kimura et al. [16] suggested that GAD1 expression can control $\beta$-catenin localization that further activates the downstream genes playing key roles in tumorigenesis and metastasis. These findings may further support the identification of GAD1 overexpression is correlated with advanced NPC diseases in the current study. Although this factor remains unclear, it can serve as a treatment target for advanced-stage NPC patients with resistance to cisplatin-based radiotherapy to enable them benefit from investigatory small $\beta$-catenin inhibitors [51]. Moreover, the glutamine-glutamate/GABA cycle influences GABA metabolism through GAD1 [15]. Li et al. [52] reported an overexpression of GABA and GABA receptors in hepatocellular carcinoma. Hence, on the basis of our findings, we suggest incorporating GABAergic system agonists into adjuvant therapy for patients with advanced NPC.

In this present study, we did not investigate endogenous GAD1 mRNA and protein levels in NPC through Western blot or reverse transcription polymerase chain reaction that could further support the observed high GAD1 expression as a poor prognosticator. A large-scale study is required to clarify the association between the GAD1 protein and $\beta$-catenin expression in NPC.

In conclusion, this study is the first to report that GAD1 overexpression is associated with an advanced tumor status. Furthermore, the overexpression serves as a critical prognosticator of early local recurrence and distant metastasis in patients with early and locoregionally advanced NPC. Our findings strengthen the potential role of GAD1 in contributing to tumor invasiveness in NPC and reveal that GAD1 is a novel therapeutic target for treatment.

\section{Ethical Standard}

This study was approved by the Institutional Review Board (IRB) of Chi Mei Medical Center (IRB10501-006). All samples were obtained from the BioBank of Chi Mei Medical Center and had been previously collected following official ethical guidelines. Informed consent has been obtained for those enrolled into BioBank.

\section{Authors' Contributions}

Conception and design: Y-Y Lee, C-Y Lin, C-F Li; Development of methodology: T-B Chao, S-W Lee, Li, C-F Li; Acquisition of data: M-J Sheu; Analysis and interpretation of data: Y-F Tian, T-J Chen, H-L He; Writing and/or revision of the manuscript: Y-Y Lee, I-W Chang, C-H Hsing, C-F Li; Study supervision: C-Y Lin, C-F Li. 


\section{Competing Interests}

The authors declare no potential conflicts of interest.

\section{References}

1. Wei WI, Sham JS. Nasopharyngeal carcinoma. Lancet. 2005;365:2041-54.

2. Tsao SW, Yip YL, Tsang CM, Pang PS, Lau VM2, et al. Etiological factors of nasopharyngeal carcinoma. Oral Oncol. 2014;50:330-8.

3. Shi S, Li X, You B, Shan Y, Cao X, You Y. High Expression of FGFR4 Enhances Tumor Growth and Metastasis in Nasopharyngeal Carcinoma. J Cancer. 2015;6:1245-54.

4. Jiang Q, Zhang Q, Wang S, Xie S, Fang W, Liu Z, et al. A Fraction of CD133+ CNE2 Cells Is Made of Giant Cancer Cells with Morphological Evidence of Asymmetric Mitosis. J Cancer. 2015;6:1236-44.

5. Barnes L, Eveson JW, Reichart P, Sidransky D. World Health Organization Classifiation of Tumors. Pathology and Genetics of Head and Neck Tumours. IARC Press: Lyon; 2005.

6. Xiao K, Yu Z, Li X, Li X, Tang K, Tu C, et al. Genome-wide Analysis of Epstein-Barr Virus (EBV) Integration and Strain in C666-1 and Raji Cells. J Cancer. 2016;7:214-24

7. Hui EP, Ma BB, Leung SF, King AD, Mo F, Kam MK, et al. Randomized phase II trial of concurrent cisplatin-radiotherapy with or without neoadjuvant docetaxel and cisplatin in advanced nasopharyngeal carcinoma. Journal of clinical oncology.2009; 27: 242-249.

8. Baujat B, Audry H, Bourhis J, Chan AT, Onat H, Chua DT, et al. Chemotherapy in locally advanced nasopharyngeal carcinoma: an individual patient data meta-analysis of eight randomized trials and 1753 patients. Int J Radiat Oncol Biol Phys 2006; 64: 47-56.

9. Lee $\mathrm{AW}$, Lin JC, Ng WT. Current management of nasopharyngeal cancer. Semin Radiat Oncol. 2012;22:233-44.

10. Chen YP, Guo R, Liu N, Liu X, Mao YP, Tang LL, et al. Efficacy of the Additional Neoadjuvant Chemotherapy to Concurrent Chemoradiotherapy for Patients with Locoregionally Advanced Nasopharyngeal Carcinoma: a Bayesian Network Meta-analysis of Randomized Controlled Trials. J Cancer. 2015;6:883-92.

11. Tham IW, Lu JJ. Controversies and challenges in the current management of nasopharyngeal cancer. Expert Rev Anticancer Ther. 2010;10:1439-50.

12. Tennant DA, Durán RV, Gottlieb E. Targeting metabolic transformation for cancer therapy. Nat Rev Cancer. 2010;10:267-77.

13. Hanahan D, Weinberg RA. Hallmarks of cancer: the next generation. Cell. 2011;144:646-74.

14. Cairns RA, Harris IS, Mak TW. Regulation of cancer cell metabolism. Nat Rev Cancer. 2011;11:85-95

15. Walls AB, Waagepetersen HS, Bak LK, Schousboe A, Sonnewald U. The glutamine-glutamate/GABA cycle: function, regional differences in glutamate and GABA production and effects of interference with GABA metabolism. Neurochem Res. 2015;40:402-9.

16. Kimura R, Kasamatsu A, Koyama T, Fukumoto C, Kouzu Y, Higo M, et al. Glutamate acid decarboxylase 1 promotes metastasis of human oral cancer by $\beta$-catenin translocation and MMP7 activation. BMC Cancer. 2013;13:555.

17. $\mathrm{Bu} \mathrm{DF}$, Erlander MG, Hitz BC, Tillakaratne NJ, Kaufman DL, Wagner-McPherson CB, et al. Two human glutamate decarboxylases, $65-\mathrm{kDa}$ GAD and 67-kDa GAD, are each encoded by a single gene. Proc Natl Acad Sci USA. 1992;89:2115-19.

18. Chessler SD, Lernmark A. Alternative splicing of GAD67 results in the synthesis of a third form of glutamic-acid decarboxylase in human islets and other non-neural tissues. J Biol Chem. 2000;275:5188-92.

19. Akbarian S, Huang HS. Molecular and cellular mechanisms of altered GAD1/GAD67 expression in schizophrenia and related disorders. Brain Res Rev. 2006:52:293-304.

20. Kaufman DL, Erlander MG, Clare-Salzler M, Atkinson MA, Maclaren NK, Tobin AJ. Autoimmunity to two forms of glutamate decarboxylase in insulin-dependent diabetes mellitus. J Clin Invest. 1992;89:283-92.

21. Maemura K, Yamauchi H, Hayasaki H, Kanbara K, Tamayama T, Hirata I, et al. Gamma-amino-butyric acid immunoreactivity in intramucosal colonic tumors. J Gastroenterol Hepatol 2003; 18: 1089-1094.

22. Yan $\mathrm{H}$, Tang G, Wang H, Hao L, He T, Sun X,et al. DNA methylation reactivates GAD1 expression in cancer by preventing CTCF-mediated polycomb repressive complex 2 recruitment. Oncogene. 2015 Nov 9. doi: 10.1038/onc.2015.423. [Epub ahead of print]

23. Azuma $\mathrm{H}$, Inamoto $\mathrm{T}$, Sakamoto $\mathrm{T}$, Kiyama $\mathrm{S}$, Ubai $\mathrm{T}$, Shinohara $\mathrm{Y}$, et al. Gamma-aminobutyric acid as a promoting factor of cancer metastasis; induction of matrix metalloproteinase production is potentially its underlying mechanism. Cancer Res. 2003; 63: 8090-8096.

24. Jaraj SJ, Augsten M, Haggarth L, Wester K, Ponten F, Ostman A, et al. GAD1 is a biomarker for benign and malignant prostatic tissue. Scand J Urol Nephrol. 2011;45: 39-45.

25. Andang M, Hjerling-Leffler J, Moliner A, Lundgren TK, Castelo-Branco G, Nanou E et al. Histone H2AX-dependent GABA(A) receptor regulation of stem cell proliferation. Nature. 2008; 451: 460-464.
26. Sengupta S, den Boon JA, Chen IH, Newton MA, Dahl DB, Chen M, et 1 . Genome-wide expression profiling reveals EBV-associated inhibition of MHC class I expression in nasopharyngeal carcinoma. Cancer Res. 2006;66:7999-8006.

27. Lan J, Huang HY, Lee SW, Chen TJ, Tai HC, Hsu HP, et al. TOP2A overexpression as a poor prognostic factor in patients with nasopharyngeal carcinoma. Tumour Biol. 2014;35:179-87.

28. Lee YE, He HL, Lee SW, Chen TJ, Chang KY, Hsing $\mathrm{CH}$, et al. AMACR overexpression as a poor prognostic factor in patients with nasopharyngeal carcinoma. Tumour Biol. 2014;35:7983-91.

29. Lee YE, He HL, Chen TJ, Lee SW, Chang IW, Hsing CH, et al. The prognostic impact of RAP2A expression in patients with early and locoregionally advanced nasopharyngeal carcinoma in an endemic area. Am J Transl Res. 2015;7:912-21.

30. Edge SB, Byrd DR, Compton CC, Fritz AG, Greene FL, Trotti A. AJCC cancer staging manual; 7th ed. Heidelberg: Springer. 2010

31. Wolden SL, Zelefsky MJ, Kraus DH, Rosenzweig KE, Chong LM, Shaha AR, et al. Accelerated concomitant boost radiotherapy and chemotherapy for advanced nasopharyngeal carcinoma. J Clin Oncol. 2001;19:1105-10.

32. Lin JC, Jan JS, Hsu CY, Liang WM, Jiang RS, Wang WY. Phase iii study of concurrent chemoradiotherapy versus radiotherapy alone for advanced nasopharyngeal carcinoma: positive effect on overall and progression-free survival. J Clin Oncol. 2003;21:631-7.

33. Liang XX, Li Q, Su Z, Lan XW, Ouyang PY, Mao YP, et al. Significant prognostic impact of chemoradiotherapy-induced hemoglobin decrease on treatment outcomes of nasopharyngeal carcinoma. J Cancer. 2015;6:502-10.

34. Spratt DE, Lee N. Current and emerging treatment options for nasopharyngeal carcinoma. Oncol Targets Ther. 2012;5:297-308.

35. Tsao SW, Tsang CM, To KF, Lo KW. The role of Epstein-Barr virus in epithelial malignancies. J Pathol. 2015;235:323-33.

36. Erdo SL, Wolff JR. g-aminobutyric acid outside the mammalian brain. J. Neurochem. 1990; 54: 363-72

37. Joh TH, Baetge EE, Ross ME, Lai CY, Docherty M, Bradford H et al. Genes for neurotransmitter synthesis, storage, and uptake. Fed Proc. 1985; 44:2773-2779.

38. Negri FV, Wotherspoon A, Cunningham D, Norman AR, Chong G, Ross PJ. Mucinous histology predicts for reduced fluorouracil responsiveness and survival in advanced colorectal cancer. Ann Oncol. 2005;16: 1305-1310.

39. Maisano R, Azzarello D, Maisano M, Mafodda A, Bottari M, Egitto G,et al. Mucinous histology of colon cancer predicts poor outcomes with FOLFOX regimen in metastatic colon cancer. J Chemother. 2012; 24: 212-216.

40. Roberts SS, Mendonca-Torres MC, Jensen K, Francis GL, Vasko V. GABA receptor expression in benign and malignant thyroid tumors. Pathol Oncol Res. 2009;15: 645-650.

41. Liu Y, Li YH, Guo FJ, Wang JJ, Sun RL, Hu JY, et al. Gamma-aminobutyric acid promotes human hepatocellular carcinoma growth through overexpressed gamma-aminobutyric acid A receptor alpha 3 subunit. World J Gastroenterol . 2008;14: 7175-7182.

42. Takehara A, Hosokawa M, Eguchi H, Ohigashi H, Ishikawa O, Nakamura Y, et al. Gamma-aminobutyric acid (GABA) stimulates pancreatic cancer growth through overexpressing GABAA receptor pi subunit. Cancer Res. 2007;67: 9704-9712.

43. Young SZ, Bordey A. GABA's control of stem and cancer cell proliferation in adult neural and peripheral niches. Physiology (Bethesda). 2009;24:171-185

44. Ippolito JE, Piwnica-Worms D. A fluorescence-coupled assay for gamma aminobutyric acid (GABA) reveals metabolic stress-induced modulation of GABA content in neuroendocrine cancer. PLoS One. 2014;9:e88667.

45. Epstein JI, Egevad L, Amin MB, Delahunt B, Srigley JR, Humphrey PA; Grading Committee. The 2014 International Society of Urological Pathology (ISUP) Consensus Conference on Gleason Grading of Prostatic Carcinoma: Definition of Grading Patterns and Proposal for a New Grading System. Am J Surg Pathol. 2016;40:244-52.

46. Kruck S, Eyrich C, Scharpf M, Sievert KD, Fend F, Stenzl A, et al. Impact of an altered Wnt $1 / \beta$-catenin expression on clinicopathology and prognosis in clear cell renal cell carcinoma. Int J Mol Sci. 2013, 14:10944-10957.

47. Sawada $G$, Ueo $H$, Matsumura $T$, Uchi $R$, Ishibashi $M$, Mima $K$, et al. $C H D 8$ is an independent prognostic indicator that regulates $\mathrm{Wnt} / \beta$-catenin signaling and the cell cycle in gastric cancer. Oncol Rep. 2013;30:1137-1142.

48. Abd El-Rehim D, Ali MM: Aberrant expression of $\beta$-catenin in invasive ductal breast carcinomas. J Egypt Natl Canc Inst 2009; 21:185-195

49. Xu L, Jiang Y, Zheng J, Xie G, Li J, Shi L, Fan S. Aberrant expression of $\beta$-catenin and E-cadherin is correlated with poor prognosis of nasopharyngeal cancer. Hum Pathol. 2013;44:1357-64.

50. $\mathrm{Hu} \mathrm{W}$, Xiao L, Cao C, Hua S, Wu D. UBE2T promotes nasopharyngeal carcinoma cell proliferation, invasion, and metastasis by activating the AKT/GSK3 $\beta / \beta$-catenin pathway. Oncotarget. 2016;7:15161-72.

51. Thakur R, Mishra DP. Pharmacological modulation of beta-catenin and its applications in cancer therapy. J Cell Mol Med. 2013;17:449-56.

52. Li YH, Liu Y, Li YD, Liu YH, Li F, Ju Q, et al. GABA stimulates human hepatocellular carcinoma growth through overexpressed GABAA receptor theta subunit. World J Gastroenterol. 2012;18:2704-11. 